\title{
Awareness and Practices on Disaster Risk Preparedness of Maritime Students
}

\author{
Abegail P. Panase ${ }^{1}$ and Ma. Elena Y. Doruelo ${ }^{2}$ \\ ${ }^{1}$ St. Therese MTC Colleges, Iloilo City, Philippines \\ ${ }^{2}$ Carlos Hilado Memorial State College, Talisay City, Philippines
}

\begin{tabular}{l} 
Article history \\
Submitted: 23 July 2020 \\
Revised: 10 November 2020 \\
Accepted: 12 November 2020 \\
\hline Keywords \\
Education \\
Management \\
Disaster Risk Preparedness \\
Awareness \\
Practices \\
Maritime Students \\
Descriptive-Correlational \\
Iloilo City
\end{tabular}

\section{Article history}

Submitted: 23 July 2020

Revised: 10 November 2020

2020
Introduction. Disaster preparedness is a measure in which individuals or groups developed plans, allocated resources, and established procedures for implementing the program in case of emergency. Alarming cases of maritime disasters have occurred in the Philippines in the past years. These incidents have created damage to property and loss of lives. They have placed the credibility of maritime officers and the maritime industry in question. These cause a catastrophic impact on the environment as well as on marine life. Hence, the paper describes the level of awareness and extent of the practice of disaster risk preparedness of maritime students of St. Therese MTC Colleges, School Year 2019-2020 at Iloilo City. Likewise, it explores the awareness and extent practices of maritime students. Moreover, it determines the correlation among awareness and extent practices on disaster risk preparedness of maritime students.

Methods. A descriptive-comparative and correlational research examined the relationship between awareness and practices on disaster risk preparedness of the maritime students of St. Therese MTC Colleges during School Year 2018-2019. Using stratified random sampling, 312 students participated in the study. The data was gathered using the Office of Civil Defense Disaster Risk Preparedness Manual (2015). Mean, Standard Deviation, t-test, and Pearson r were used to analyze the data.

Results. The findings of the study revealed that the level of awareness on disaster risk preparedness of the maritime students is generally very high when grouped according to academic programs, in the areas of fire and natural hazards such as typhoon, flood, thunderstorm, storm surge, landslide, earthquake, tsunami, volcanic eruption, and tornado. Moreover, the extent of the practices on disaster risk preparedness as a whole is very high when students are grouped according to academic programs, in the areas of fire and natural hazards such as typhoon, flood, thunderstorm, storm surge, landslide, earthquake, tsunami, volcanic eruption, and tornado. Comparatively, there is no significant relationship between awareness and extent of practices on the disaster risk preparedness of maritime students in the areas of fire and natural hazards such as typhoon, flood, thunderstorm, storm surge, landslide, earthquake, tsunami, volcanic eruption, and tornado. Moreover, it was found that there is a significant relationship between the awareness and extent of practices on the disaster risk preparedness between the Bachelor of Marine Transportation (BSMT) and Bachelor of Marine Engineering students in the areas of fire and natural hazards such as typhoon, flood, thunderstorm, storm surge, landslide, earthquake, tsunami, volcanic eruption, and tornado.

Conclusion. The school program on disaster risk preparedness of maritime students, awareness, and practices is essential in fostering a better level of awareness and extent practices on disaster risk preparedness of students. Teachers, as well as the administration, have a huge responsibility in designing programs to create substantial awareness and practices on disaster risk preparedness to the school community, and also to ensure and protect students from unwanted incidents either inside the campus or on their way to school, which suggest that education is an essential factor in reducing the impact of natural disasters and intensified education and awareness inculcate a culture of disaster preparedness in students and empower them to the make right decisions in times of emergency. The very high level of the extent of practices on disaster risk preparedness of the maritime students shows that students are consistently aware and prepared for any disaster that will come their way. It implies 
that the maritime students are fully aware and have great practices on disaster risk preparedness based on the findings.

Practical Value of the Paper. The study significantly contributes to the few existing literature on the awareness and extent practices on disaster risk preparedness of maritime students. In addition, the findings of the study may also serve as a basis for school administrators in implementing school programs, which can help improve the students' awareness and practices regarding disaster response. Finally, this study may serve as an eye-opener for other researchers to conduct the same topic in the broader scope and coverage.

\section{References}

Ajzen, I. (1991). The theory of planned behavior. Organizational behavior and human decision processes, 50(2), $179-211$.

Austin, D. W. (2012). Preparedness clusters: A research note on the disaster readiness of community-based organizations. Sociological Perspectives, 55(2), 383-393.

Barranta, C. (2012). Emotional intelligence and personality traits of Filipino seafarers and their attitude towards the work environment.

Clerveaux, V., Spence, B., \& Katada, T. (2010). Promoting disaster awareness in multicultural societies: the DAG approach. Disaster Prevention and Management: An International Journal.

Cunningham, S. B. (2015). The relevance of maritime education and training at the secondary level.

Jurilla, V. D. (2016). A Case Analysis of Disaster Risk Reduction Preparedness of Iloilo Province: Basis for A Comprehensive Intervention Program. Asia Pacific Journal of Multidisciplinary Research, 4(3).

Mulyasari, F., Takeuchi, Y., \& Shaw, R. (2011). Implementation tools for disaster education. In Disaster education. Emerald Group Publishing Limited.

Surugiu, F., Nistor, C., \& Cojanu, G. (2010). Impact of Seafarers Training on Crew Personnel Strategy and Competitiveness. Maritime Transport \& Navigation Journal, 2(2), 60-65.

\section{Correspondence:}

Abegail P. Panase [abegailpanase18@gmail.com]

https://orcid.org/0000-0003-0718-081X 